\title{
The attitude and basic knowledge of insulin pump therapy among healthcare providers.
}

\author{
Sultan Alghadeer ${ }^{*}$, Khaled Aljuaydi², Miteb Alanazi ${ }^{3}$, Bander Balkhi ${ }^{1}$, Abdulaziz Alhossan ${ }^{1}$, Yazed \\ Alruthia ${ }^{1}$ \\ ${ }^{1}$ Department of Clinical Pharmacy, College of Pharmacy, King Saud University, Saudi Arabia \\ ${ }^{2}$ Department of Emergency, King Saud University, Medical City, Saudi Arabia \\ ${ }^{3}$ Department of Pharmacy, King Saud University, Medical City, Saudi Arabia
}

\begin{abstract}
Purpose: Lack of basic knowledge and ineffective counselling on insulin pumps among healthcare providers could contribute to the inappropriate use of insulin pumps. The aim of this study is to assess the attitude and basic knowledge of insulin pump therapy among health care providers.

Method: Cross-sectional study using a developed validated questionnaire was conducted among 81 healthcare providers to assess the knowledge and attitudes toward the use of insulin pump.

Result: Almost 73\% (n=60) of participants believe that knowing the basic information and understanding the primary principles of insulin pump therapy is very important, $50.7 \%(n=41)$ believes that insulin pump therapy promotes patient emotionally and psychologically and is able to improve the management of uncontrolled blood glucose, and $64.2 \%(n=52)$ assumes that the cost of insulin pump therapy was seen as one of the major barriers of using the pump from the healthcare providers' point of view. The majority of responses $(80 \% ; n=65)$ did not know the basic components of insulin pump and 79\% ( $n=64)$ did not know that insulin pump can be loaded with insulin by the patients themselves based on their need.

Conclusion: Lack of knowledge among most healthcare providers towards using insulin pumps was noticeable, and therefore; educational programs, professional seminars, and continuous professional educational hours about the basic knowledge and primary principles of insulin pump therapy are needed for all healthcare providers.
\end{abstract}

Keywords: Knowledge, Attitude, Insulin pumps, Healthcare providers, Diabetes.

Accepted on April 16, 2019

\section{Introduction}

An insulin pump or continuous subcutaneous insulin infusion (CSII) is a programmable device that can mimic physiological insulin secretion by the pancreas [1]. The first insulin pump was developed in the 1950s and had to be carried as a knapsack [2]. Subsequent evolution in medical technology led to the development of a pocket-sized insulin pump. The increase in insulin pump use and the advances in medical technology promoted the development of different pumps with various advantages [2]. Most pumps have similar basic features, but they differ in some features like reservoir size, basal rate or bolus dose increments, and waterproof design. Tubeless insulin pumps and insulin pumps connected to continuous glucose monitoring systems have recently been released in the market [3]. Despite these distinctive characteristics, all insulin pumps deliver rapid-acting insulin (lispro, aspart, and glulisine) and provide a 24-hour insulin supply in two modes: basal rate and bolus dose. The basal rate mode is pre-programmed to deliver insulin continuously throughout the day, while the bolus dose mode can be manually programmed to deliver preprandial insulin doses.

Insulin pump therapy or CSII has been shown to be effective and safe [4]. Several systematic reviews and meta-analyses have compared the efficacy of 2 different forms of insulin delivery, the insulin pump and multiple dose injections (MDI), and have found that the use of the insulin pump is associated with better glycemic control in patients with type-1 diabetes with no difference being observed in the incidence of severe hypoglycemia between the insulin pump and MDI groups. In addition, insulin pump therapy was associated with improved levels of patient satisfaction and quality of life, as reported by participants [4-8]. Similar findings were observed in paediatric patients with type-1 diabetes [6,8-10].

Insulin pump use was associated with a very low rate of hospitalization ( 0.18 hospitalizations/year) and $93 \%$ patient satisfaction, with $95 \%$ patients encouraging the use of insulin 
pumps [11]. These high levels of satisfaction and tolerance stem from the several benefits of using insulin pumps. Insulin pumps ensure precise and predictable insulin delivery, allow for a more flexible lifestyle, and estimate the insulin dose needed based on carbohydrate consumption $[12,13]$.

Despite their numerous benefits, insulin pumps are associated with potential adverse effects such as diabetic ketoacidosis, severe hypo/hyperglycemia, infections, and dermatological complications $[5,14]$. One study showed that $43 \%$ pediatric patients who experienced insulin pump-associated adverse effects required hospital admission, with diabetic ketoacidosis and severe hyperglycemia being the most common reasons for hospitalization [15].

The adverse effects associated with insulin pumps result mainly from their inappropriate use. Lack of basic knowledge and ineffective counseling by healthcare providers on insulin pump usage could contribute to the inappropriate use of insulin pumps. Several precautionary measures and guidance for insulin pump usage have been released to bust misconceptions regarding insulin pump therapy $[16,17]$.

Recently, a massive increase in insulin pump use has been observed. Twenty to twenty-five percent of patients with type-1 diabetes are estimated to use insulin pumps in the U.S. versus $10 \%$ in some countries in Europe [2]. However, no data are available to measure the prevalence of insulin pump use in Saudi Arabia. In addition, no study has been conducted to assess the level of knowledge and understanding of insulin pump therapy among healthcare providers. The aim of this study was to assess the attitude toward and basic knowledge of insulin pump therapy among healthcare providers in Saudi Arabia.

\section{Method}

A cross-sectional study using a developed questionnaire was conducted at King Saud University Medical City (KSUMC) from July 1 to September 1, 2016. The ethical approval was granted from the institutional review board (IRB) at KSUMC (IRB Project No. E-16-2030). The questionnaire used in this study was formulated from literature and organizations such as American Diabetes Association and National Institute for Health and Care Excellence. The questionnaire was validated by a group of 7 experts. Post-validation, a pilot study was undertaken to assess the feasibility of our survey. Then, the main survey using the face-to-face method was conducted with healthcare providers including physicians and physician interns, nurses, and pharmacists and pharmacist interns. Any healthcare provider who was in the first year of school was excluded.

Data collected included demographic data, the attitude of healthcare providers toward the use of insulin pumps, and knowledge of basic information regarding insulin pumps. The questionnaire comprised 10 multiple-choice questions. Scores were calculated as the sum of the correct answers; the highest possible score was 10 . After slight modifications were made to the questionnaire based on feedback received on the pilot survey, the knowledge section was validated by experts and the reliability test, Cronbach's alpha (alpha $=0.8$ ). The insulin pump attitude section was developed to evaluate healthcare providers' attitudes toward the use of insulin pumps. The questionnaire comprised 10 questions. The healthcare providers were expected to respond to each question by choosing options from a 5-point Likert scale: strongly disagree, disagree, neutral, agree, and strongly agree. After the pilot survey, Cronbach's alpha for the questionnaire was determined to be 0.7 .

The main objective of our study was to assess the attitude toward and basic knowledge of insulin pump therapy among healthcare providers. The data were analyzed using SPSS version 22 for Windows. Descriptive statistics were used to analyze the data including numbers, percentages, and means ( \pm standard deviation).

\section{Results}

\section{Participants}

A total of 81 healthcare providers working at King Saud University Medical City (KSUMC) participated in this study. Most of the participants $(58 \% ; n=47)$ were female, and $65.4 \%$ $(n=53)$ were between 20 and 30 years of age. Nearly two-thirds of the participants had less than 3 years of experience. Out of 81 participants, $11.1 \%(\mathrm{n}=9)$ were MD consultants; $3.7 \%$ $(\mathrm{n}=3)$, hospital pharmacists; $23.4 \%(\mathrm{n}=19)$, nurses; $30.8 \%$ $(n=25)$, residents; and $30.8 \%(n=25)$, interns. Most of the participants $(79 \% ; n=64)$ had never seen an insulin pump, 9 reported seeing an insulin pump only once a year, and 3 participants reported seeing it more than 3 times a year. Demographic data of the participants are shown in Table 1.

\section{Measures}

Attitude of healthcare providers toward insulin pumps: Table 2 represents the responses of healthcare providers to various questions regarding their attitude toward insulin pump therapy. Most of the respondents $(74 \% ; n=60)$ believed that knowing basic information regarding insulin pump therapy and understanding its primary principles are very important. Although $63 \%(n=51)$ of the participants either agreed or strongly agreed that each hospital should have a certified diabetes educator with expertise in insulin pumps, about $19.7 \%$ $(\mathrm{n}=16)$ believed that this was not important. A high percentage $(50.7 \% ; n=41)$ of participants believed that insulin pump therapy benefits patients emotionally and psychologically and can improve the management of blood glucose levels. From the healthcare providers' point of view, the cost of insulin pump therapy was one of the major barriers to the use of the pump. Nearly half of the participants believed that to promote the use of insulin pumps, it is important to have an educational program regarding their use, benefits, and risk.

Knowledge regarding insulin pumps among healthcare providers: Most of the participants claimed to have sufficient knowledge regarding the main function of insulin pump therapy. However, half of them did not know what type of 
insulin should be used in the pump or to whom the insulin pump should be recommended. Most of the participants $(80 \%$; $\mathrm{n}=65$ ) did not know the basic components of an insulin pump, and $79 \%(n=64)$ did not know that insulin pumps could be loaded with insulin by the patients themselves based on their requirements. Only $15 \%(n=12)$ of the participants had knowledge about the infusion set of the insulin pump. There was a high percentage of uncertainty among the participants about the variances in the types of insulin pumps. Additionally, only few participants knew about the disconnection procedure of the pump and the need for self-monitoring (finger-stick) blood glucose levels while using the pump (Table 3).

Scores received by healthcare providers on their knowledge of and attitude toward insulin pump therapy: Attitude and knowledge evaluations were classified into common themes and were compared among the healthcare providers that participated in the study (Table 4). The attitude measurements were divided into the following themes: the importance of knowing the primary principles of insulin pump therapy, the need for certified educators and structured programs, the demand for educational programs for healthcare providers, and lastly, barriers, motivators, and candidates for insulin pump therapy. We found that pharmacists had more knowledge about the basic information and primary principles of insulin pump therapy than did other healthcare providers. Pharmacists also seconded the need to have certified educators and structured programs. However, physicians were more likely to appreciate the value and importance of having educational programs about insulin pumps.

The knowledge measurements were divided into 4 different themes: the role and type of insulin in the pump, common characteristics of insulin pump therapy, basic information and features of insulin pump therapy, and common myths regarding insulin pump therapy. Overall, physicians had a highest mean knowledge score, followed by pharmacists and nurses.

Table 1. Demographic characteristics of the participants.

\begin{tabular}{ll}
\hline Characteristics & n (Percentage) \\
\hline Age & \\
\hline $20-30$ & $53(65.43 \%)$ \\
\hline $31-40$ & $18(22.22 \%)$ \\
\hline
\end{tabular}

\begin{tabular}{|c|c|}
\hline $41-50$ & $8(9.88 \%)$ \\
\hline$>50$ & $2(2.47 \%)$ \\
\hline \multicolumn{2}{|l|}{ Gender } \\
\hline Male & $34(42)$ \\
\hline Female & $47(58)$ \\
\hline \multicolumn{2}{|l|}{ Current position } \\
\hline MD consultant & $9(11.1)$ \\
\hline MD resident & $16(19.7)$ \\
\hline MD intern & $17(21)$ \\
\hline Clinical pharmacist & $3(3.7)$ \\
\hline Pharmacy resident & $9(11.1)$ \\
\hline Pharmacy intern & $4(4.9)$ \\
\hline Nurse & $19(23.5)$ \\
\hline Nurse intern & $4(4.9)$ \\
\hline \multicolumn{2}{|l|}{ Years of experience } \\
\hline$<1$ year & $26(32.1)$ \\
\hline $1-3$ & $24(29.6)$ \\
\hline $3-5$ & $9(11.1)$ \\
\hline$>5$ years & $22(27.2)$ \\
\hline \multicolumn{2}{|c|}{ Ever Seen an insulin pump } \\
\hline Yes & $17(21)$ \\
\hline No & $64(79)$ \\
\hline \multicolumn{2}{|c|}{ How often they saw the insulin pump } \\
\hline $1 /$ month & $0(0 \%)$ \\
\hline 2-3 time/month & $0(0 \%)$ \\
\hline$>3$ time/month & $0(0 \%)$ \\
\hline $1 /$ year & $9(52.94 \%)$ \\
\hline 2-3 time/year & $5(29.41 \%)$ \\
\hline$>3$ time/year & $3(17.65 \%)$ \\
\hline
\end{tabular}

Table 2. Attitude of healthcare providers toward insulin pump therapy.

\begin{tabular}{|c|c|c|c|c|c|}
\hline Measures & Strongly Agree n (\%) & Agree n (\%) & No Comments n (\%) & Disagree $\mathrm{n}(\%)$ & Strongly Disagree $\mathrm{n}(\%)$ \\
\hline $\begin{array}{l}\text { Healthcare providers should know the basic } \\
\text { information and understand primary } \\
\text { principles of insulin pump therapy. }\end{array}$ & $27(33.3 \%)$ & $33(40.7 \%)$ & $8(9.9 \%)$ & $12(14.8 \%)$ & $1(1.2 \%)$ \\
\hline $\begin{array}{l}\text { Each hospital should have a certified } \\
\text { diabetes educator who is an expert in } \\
\text { dealing with insulin pumps. }\end{array}$ & $22(27.2 \%)$ & $29(35.8 \%)$ & $14(17.3 \%)$ & $15(18.5 \%)$ & $1(1.2 \%)$ \\
\hline
\end{tabular}


Each hospital should have a structured diabetes program (start from assessment \& education, to determination \& initiation, then to outcome \& evaluation) for patients who are on insulin pump.

Insulin pump therapy promotes the patient emotionally \& psychologically to improve $22(27.2 \%)$ the management of their high blood sugar.

The selection of eligible candidate for insulin pump therapy depends more on the patient motivation and readiness than $25(30.9 \%)$ desires by healthcare providers or family.

The major barrier to insulin pump therapy is the high cost more than the associated $29(35.8 \%)$ safety issues or adverse effects.

$19(23.5 \%) \quad 22(27.2 \%) \quad 16(19.7 \%) \quad 2(2.5 \%)$

Programs, professional seminars, \& CE (continuous education) hours about the basic knowledge and primary principles of insulin pump therapy are needed for all $15(18.5)$

healthcare providers.

Educational programs for diabetic patients about the benefits \& risk of insulin pump $14(17.3 \%)$ therapy are needed.

$18(22.2 \%) \quad 22(27.2 \%) \quad 3(16 . \%) \quad 3(3.7 \%)$

Table 3. Knowledge regarding insulin pump therapy among healthcare providers.

\begin{tabular}{|c|c|c|c|}
\hline Items & Correct answer (\%) & \multicolumn{2}{|c|}{ Incorrect answer (\%) } \\
\hline 1. The main function of insulin pump therapy is: & $49(60.49)$ & $32(39.51)$ & \\
\hline 2. The type of insulin that is commonly used in the pump is: & $44(54.32)$ & $37(45.68)$ & \\
\hline 3. The main type(s) of insulin doses in the pump is(are): & $45(55.56)$ & $36(44.44)$ & \\
\hline 4. Insulin pump therapy is mainly recommended for patient with: (types of diabetes) & $40(49.38 \%)$ & $41(50.62)$ & \\
\hline 5. Insulin pump therapy can be used for: (patient population: adults, adolescents, children) & $51(62.96)$ & $30(37.04)$ & \\
\hline 6. The basic components of insulin pump are: & $16(19.75)$ & $65(80.25)$ & \\
\hline 7. Regarding the insulin pump, which of the following is Correct: (loading of insulin pumps) & $17(20.99)$ & $64(79.01)$ & \\
\hline 8. The infusion set of the insulin pump: & $12(14.81)$ & $69(85.19)$ & \\
\hline 9. The best candidate for insulin pump therapy is: & $44(54.32)$ & $37(45.68)$ & \\
\hline $\begin{array}{l}\text { 10. Answer the following with Yes, No, I Don't Know (common myths associated with using } \\
\text { insulin pumps) }\end{array}$ & Yes & No & I DON'T KNOW \\
\hline 10.1. All insulin pumps are the same & $4(4.94)$ & $33(40.74)$ & $44(54.32)$ \\
\hline 10.2. The patient needs to do very well with the new technology to be on insulin pump & $16(19.75)$ & $39(48.15)$ & $26(32.10)$ \\
\hline 10.3. The pump needs to be implanted, and therefore minor surgery is needed & $11(13.58)$ & $40(49.38)$ & $30(37.04)$ \\
\hline 10.4. The pump can't be disconnected even for short time ( $<1$ hour) & $12(14.81)$ & $27(33.33)$ & $42(51.85)$ \\
\hline $\begin{array}{l}\text { 10.5. The pump (especially if attached to continuous glucose monitoring) eliminates the } \\
\text { need for self (finger-stick) glucose monitoring }\end{array}$ & $15(18.52)$ & $21(25.93)$ & $45(55.56)$ \\
\hline
\end{tabular}

Table 4. Comparison of knowledge and attitude scores between healthcare providers toward insulin pump therapy.

\begin{tabular}{|c|c|c|c|}
\hline Measure/theme & Physicians $n=42$ & Pharmacist $n=16$ & Nurses $n=23$ \\
\hline Attitude & Mean & Mean & Mean \\
\hline The importance of knowing the basic information and primary principles of insulin pump therapy. & 3.82 & 4.13 & 3.74 \\
\hline
\end{tabular}




\begin{tabular}{|c|c|c|c|}
\hline The need for certified educator and structured program. & 3.56 & 3.94 & 3.33 \\
\hline The demand of educational programs for health care providers and patient. & 4.71 & 4.06 & 3.48 \\
\hline Barriers, motivators and candidates of insulin pump therapy. & 4.24 & 3.77 & 3.45 \\
\hline Total score & 20.15 & 15.9 & 14 \\
\hline Knowledge & & & - \\
\hline The role and type of insulin within the pump. & 2 & 1.88 & 0.96 \\
\hline Common characteristics for using insulin pump therapy. & 1.90 & 1.88 & 1.04 \\
\hline Basic information and features of insulin pump therapy. & 0.69 & 0.38 & 0.48 \\
\hline Common myths regarding the use of insulin pump therapy & 2.60 & 1.13 & 1.35 \\
\hline Total score & 7.19 & 5.27 & 3.83 \\
\hline
\end{tabular}

\section{Discussion}

Although insulin pumps have been available for a few decades now, many healthcare providers are still hesitant to recommend it to their patients. To the best of our knowledge, this is the first study, locally or globally, to assess the attitude toward and knowledge of insulin pumps among healthcare providers in different specialties. The study shows an immense lack of knowledge among most healthcare providers in different specialties regarding the patient's candidacy and/or the use of insulin pumps, which could lead to several issues: first, the underuse of insulin pumps among patients who could benefit from them; second, the incidence of serious adverse events or under treatment among patients using insulin pumps; and third, patient non-compliance due to lack of knowledge regarding the basic features of insulin pumps.

The study also showed a lack of knowledge among healthcare providers regarding the use of insulin pumps, despite educational sessions by companies selling them. This could be due to a lack of continuing education units in hospitals and medical cities. Further, since the use of these devices is restricted to specific specialties, it is important to provide training and issue licenses to all individuals who deal with these devices. In addition, healthcare providers who prescribe insulin pumps should be certified by a national agency to ensure that they have the required knowledge, and they should keep themselves updated on information regarding these devices for when they need to renew their certification.

The design of this study is cross-sectional, the sample size is small, and the participation from different disciplines are not equal, and all these make it difficult to generalize or formulate an accurate conclusion; however, it confirms the demand for more studies to evaluate the use of insulin pumps in terms of patients' candidacy and the barriers. Although most of our participants either they had never seen insulin pumps or they might see once it or three times annually, this study provides important information about the use of insulin pumps in one of the biggest and most specialized medical cities in the country. The findings of this study indicate that it is crucial that all healthcare providers who could potentially work with patients requiring insulin pumps receive sufficient education and training on the use of these devices. In addition, we recommend conducting studies that measure the impact that the lack of knowledge regarding insulin pumps among healthcare providers has on patient health and safety. Further, we recommend additional studies to evaluate the use of these devices in the country in terms of patient candidacy and the barriers to using this therapy.

\section{Conclusion}

Our study showed that most respondents believed that having basic information regarding insulin pump therapy and understanding its primary principles are important. Moreover, a high percentage of the participants believed that insulin pump therapy improves the management of blood glucose levels in patients. However, the lack of knowledge among most healthcare providers regarding the use of insulin pumps was noticeable; therefore, educational programs, professional seminars, and continuing professional education that provide basic knowledge and clarify the primary principles of insulin pump therapy are needed for all healthcare providers.

\section{Acknowledgement}

The authors extend their appreciation to the Deanship of Scientific Research at King Saud University for funding this work through the research project No: R6-17-02-41.

\section{Conflict of Interest}

No conflict of interest associated with this work.

\section{References}

1. https://www.medscape.org/viewarticle/460365.

2. Alsaleh FM, Smith FJ, Keady S, Taylor KMG. Insulin pumps: From inception to the present and toward the future. J Clin Pharm Ther 2010; 35:127-138.

3. Type 1 insulin pump therapy. Diabetes Teaching Center at the University of California, San Francisco.

4. Yeh HC, Brown TT, Maruthur N, Ranasinghe P, Berger Z, Suh YD, Wilson LM, Haberl EB, Brick J, Bass EB, 
Golden SH. Comparative effectiveness and safety of methods of insulin delivery and glucose monitoring for diabetes mellitus: a systematic review and meta-analysis. Ann Intern Med 2012; 157:336-347.

5. Pozzilli P, Battelino T, Danne T, Hovorka R, JaroszChobot P, Renard E. Continuous subcutaneous insulin infusion in diabetes: patient populations, safety, efficacy, and pharmacoeconomics. Diabetes Metab Res Rev 2015; 32:21-39.

6. Misso ML, Egberts KJ, Page M, O’Connor D, Shaw J. Continuous subcutaneous insulin infusion (CSII) versus multiple insulin injections for type 1 diabetes mellitus. Cochrane database Syst Rev. 2010; CD005103.

7. Golden SH, Brown T, Yeh HC, Maruthur N, Ranasinghe P, Berger Z, Suh Y, Wilson LM, Haberl EB, Bass EB. Methods for insulin delivery and glucose monitoring: comparative effectiveness. Agency for Healthcare Research and Quality 2012.

8. Jeitler K, Horvath K, Berghold A, Gratzer TW, Neeser K, Pieber TR, Siebenhofer A. Continuous subcutaneous insulin infusion versus multiple daily insulin injections in patients with diabetes mellitus: A systematic review and meta-analysis. Diabetologia 2008; 51:941-951.

9. Churchill JN, Ruppe RL, Smaldone A. Use of continuous insulin infusion pumps in young children with type 1 diabetes: A systematic review. J Pediatr Heal Care 2009; 23:173-179.

10. Pańkowska E, Błazik M, Dziechciarz P, Szypowska A, Szajewska H. Continuous subcutaneous insulin infusion vs. multiple daily injections in children with type 1 diabetes: A systematic review and meta-analysis of randomized control trials. Pediatr Diabetes 2009; 10:52-58.

11. Joubert M, Morera J, Vicente A, Rod A, Parienti JJ, Reznik Y. A Cross-sectional survey and retrospective analysis of a large cohort of adults with type 1 diabetes with long-term continuous subcutaneous insulin infusion treatment. J Diabetes Sci Technol 2014; 8:1005-1010.

12. http://www.diabetes.org/living-with-diabetes/treatmentand-care/medication/insulin/advantages-of-using-aninsulin-pump.html.

13. Heinemann L, Fleming GA, Petrie JR, Holl RW, Bergenstal RM, Peters AL. Insulin pump risks and benefits: A clinical appraisal of pump safety standards, adverse event reporting, and research needs. Diabetes Care 2015; 38:716-722.

14. Ross PL, Milburn J, Reith DM, Wiltshire E, Wheeler BJ. Clinical review: insulin pump-associated adverse events in adults and children. Acta Diabetol 2015; 52:1017-1024.

15. Cope JU, Samuels-Reid JH, Morrison AE. Pediatric use of insulin pump technology: A retrospective study of adverse events in children ages 1-12 years. J Diabetes Sci Technol 2012; 6:1053-1059.

16. https://www.nice.org.uk/guidance/TA151.

17. Continuous Subcutaneous Insulin Infusion (CSII) AADE White Paper. American Association of Diabetes Educators 2014.

\section{*Correspondence to}

Sultan Alghadeer

Chairman of Basic Sciences Department

Department of Clinical Pharmacy

College of Pharmacy

King Saud University

Saudi Arabia 